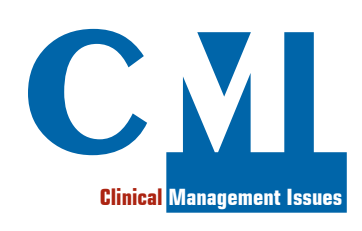

\title{
Pain control in the continuity of care
}

\begin{abstract}
As cancer is earlier diagnosed and its treatments improve, palliative care is increasingly playing a vital role in the oncology population. The concept and the timing of application of palliative care have evolved in the last decades. The WHO pain ladder and the greater understanding of appropriate multimodal pain control treatments have dramatically improved the management of cancer pain. Integration of palliative care, which appears crucial for a proper management of patients, can be defined as the provision of palliative care both during curative cancer treatment and after curative treatment has ceased. Clinical assistance should be delivered by specialised physicians in different fields, psychologists and nurses, and should include all aspects of advancedcancer care, from diagnosis to the treatment of symptoms. A further aspect of integration of palliative care concerns the role of the continuity of care in acute or emergency contexts both for out-and inpatients. Further improvements in the management of cancer pain are needed. First, the WHO ladder should be modified with further steps, like those of interventional pain control procedures and techniques, with the aim of being effective also for the small proportion of nonresponsive patients. Second, more research is needed to find out which interventions aiming to improve continuity of care of cancer patients are beneficial to improve patient, provider and process of care outcomes and to identify which outcomes are the most sensitive to change. Of crucial importance would be the development of a standardised instrument to measure the continuity of care in cancer patients.

This article is a brief overview on the management of cancer pain, from the pharmacological treatments reported by WHO ladder, to the need for integration and continuity of care.
\end{abstract}

Keywords: Palliative care; Continuity of care; Pain; Hospital care; Opioid; Interventional procedures

Controllo del dolore e continuità nelle cure

CMI 2014; 8(3): 83-90

http://dx.doi.org/10.7175/cmi.v8i3.930

\section{INTRODUCTION}

Each year 10 million people are diagnosed with cancer, of whom $70 \%$ will die of the disease and 60\% will experience significant pain $[1,2]$. As barriers to alleviate suffering associated with cancer are numerous, it became internationally imperative to declare access to pain and palliative care a human right [3].

The World Health Organization (WHO) has recommended that all countries implement comprehensive palliative care pro- grams to provide patients with pain and symptom control and psychosocial and spiritual support, and to ensure that national guidelines are adopted by all levels of care and that high coverage of patients is ensured through several options, including home care [4]. On March 2010 the Italian Republic approved a state law (38/2010) according to which all citizens in need should have free access to palliative care or pain therapy facilities. This law foresees the design of a nationwide network of three types
${ }^{1}$ University of Bologna, Department of Medical and Surgery Sciences, Bologna 2 Azienda

Ospedaliera-Universitaria di Bologna, Policlinico S. Orsola-Malpighi, Bologna

3 ANT Italia Onlus

Foundation,

Psycho-Oncology Unit, Bologna

Corresponding author Dott. Boaz Gedaliahu Samolsky Dekel Department of Medical and Surgery Sciences, University of Bologna, via Massarenti 9, 40138, Bologna Phone: 00390516363087 Fax: 00390516364439 boaz.samolskydekel@unibo.it

Disclosure

Authors declare no

competing financial interests 
of pain therapy facilities with increasingly composite proficiencies from the primary care physician to intermediate ("spoke") and high ("hub") proficiency pain centres. This approach coincides with the concept of "stratified medicine", which seeks to target therapy and make the best clinical decisions for groups of similar patients $[5,6]$. Moreover, "good policies" are needed for an effective health care system and society. In this context good policies are needed to facilitate the implementation of palliative care programs in order to provide care for all people in need of these services, ensuring impartial access to medications and therapies. Thus, good policies are needed to provide satisfactory answers to cancer patients' needs, including also accessibility to palliative care. Palliative care should be incorporated as a priority within all aspects of a national health plan. Accordingly, policies addressing essential medicines, for example, should include adequacy and availability of all palliative care medications throughout the country, so that they are made attainable wherever patients live (especially opioids for pain control) [7].

Care for cancer patients is provided by a variety of clinicians, including family physicians, oncologists, pain and palliative care specialists, and many others. In order to receive adequate access to palliative and endof-life care, continuity of care between care providers and care settings is essential. This is why more integration of palliative care into cancer treatment, throughout the disease course, is seen in major cancer centres [8].

This article provides an overview on pain management in cancer care, starting from the most adopted pharmacological treatment strategies, as reported in WHO pain ladder, and analysing in particular the importance of integration and continuity of care by health practitioners.

\section{PALLIATIVE CARE}

The concept and the timing of application of palliative care have evolved in the last decades. In 1990, the WHO defined palliative care as «the active total care of patients whose disease is not responsive to curative treatments» [9]. Indeed, palliative care was initially regarded as a specialty to care for end-stage and dying cancer patients. Nonetheless clinicians were conscious that «many aspects of palliative care are also applicable earlier in the course of the illness» [10]. In recent years, along with the longer survival of cancer patients and congruent progression of their needs, the conversion, through treatment advances, of many cancers into chronic diseases, and the recognition that palliative treatments cannot be based on life expectancy, the definition and role of palliative care has progressed. In 2012, palliative care has been defined as specialised medical care for people with serious illnesses. This type of care is focused on providing patients and families with relief from the symptoms, pain, stress, and to improve their quality of life whatever the diagnosis. Thus, palliative care is appropriate at any age and at any stage in a serious illness, and can be provided together with curative treatment [11].

"Palliative care" includes not only pain and symptom management, but also psychosocial support for patients and families, that may be provided concurrently with cancer treatment or after cancer treatment has ended. Palliative care, including pain therapy, may be (or, better, should be) provided at any point during the disease course, from diagnosis to death [12].

Successful management of cancer pain begins with an adequate and full assessment of the pain pathophysiology, qualitative, quantitative, and temporal aspects. A comprehensive knowledge of the underlying pathophysiology of pain is essential for effective management. With effective assessment and a systematic approach to the choice of analgesics, over $80 \%$ of cancer pain can be controlled with the use of inexpensive drugs that can be self-administered by mouth at regular intervals. Consideration must always be given to treating the underlying cause of the pain by means of surgery, radiotherapy, chemotherapy, or other appropriate measures of analgesia techniques.

Due to the high number of physicians who may visit a patient in as many different health care settings, the responsibility for the overall management of the patient's pain may be unclear. Further fragmentation can occur due to lack of communication between the hospital and the community care setting, a problem exacerbated by incomplete and inconsistent documentation of pain. In the region of Emilia Romagna, Italy, a pain diary has been developed as a follow up instrument [13]. Patients self report on this personal diary their daily pain scores and therapy and ideally they may make it available anytime they interact with health care 
providers. Such instrument is of extreme importance for a fluent continuity of care, even when a patient is taken care of by different specialists at different times and at different settings.

\section{THE WHO PAIN LADDER}

The WHO pain ladder [14] is a practical conceptual paradigm introduced almost 30 years ago to describe guidelines for the use of analgesic drugs in the management of pain. It was originally thought to be used in the management of cancer pain, but is now widely used by professionals for the management of pain also in non-cancer patients. The WHO pain ladder implies the use of a limited number of relatively inexpensive medications in a stepwise approach. It helped legitimise the use of opioids for treatment of cancer pain and stimulated multiple educational campaigns worldwide on the use, benefits, and side effects of drugs in the treatment of pain. This paradigm is part of 5 simple recommendations for the correct use of analgesics to make the prescribed treatments effective. These recommendations include prescription of analgesics by mouth, by the clock, by the ladder, for the individual and with attention to details. In particular, when possible, oral analgesics should be privileged; they should be given at regular intervals; should be prescribed according to pain intensity as evaluated by a scale of pain intensity; the dosing of analgesics should be tailored to the individual; and any effort should be made so that the patients, their family, and caregivers will all have the necessary information about when and how to administer the medications. The 1986 version of the WHO analgesic ladder asserts that treatment of pain, based on its intensity, should begin with a nonopioid medication. If the pain is still not controlled, then a weak opioid should be introduced; if even these medications are insufficient, strong opioids should be started. Further, nonopioid medications can be added at each of the ladder steps; two analgesics of the same category should not be used simultaneously. The analgesic ladder also includes the possibility of adding adjuvant treatments for neuropathic pain or for symptoms associated with cancer and with ongoing treatments. The literature on this approach effectiveness asserts that this paradigm offers inexpensive treatment and adequate relief for $70 \%$ to $90 \%$ of can- cer patients with pain [15]; however, these proportions have been questioned, and the range is now thought to be $70 \%$ to $80 \%$ $[16,17]$.

\section{INTERVENTIONAL PROCEDURES AND TECHNIQUES}

The WHO pain ladder and the greater understanding of appropriate multimodal pain control treatments have dramatically improved the management of cancer pain. However, while the WHO method is effective in most patients, a consistent proportion do not have their pain controlled adequately, even with optimised systemic therapy: some pains, like bone, neuropathic and visceral pain, are resistant to opioid treatments. This has led to the suggestion that the WHO ladder should be modified with a fourth (or fifth) step, that of interventional procedures and techniques [18-21].

The specialty of pain medicine evolved to increased experience and skills in pharmacological management of pain and in implant and infusion techniques. The UK NICE guidance on supportive and palliative care in cancer advocates that each local palliative care multidisciplinary team should have access to pain specialists with expertise in nerve blocking and neuro-modulation techniques [18].

There is a wide range of potential interventional procedures, including:

- Neuraxial delivery of analgesic drugs, and destruction of spinal and radicular nerve pathways.

- Interruption of pain pathways travelling via the sympathetic nervous system, local anaesthetic and destructive techniques directed to peripheral nerves.

- Other procedures, including minimally invasive treatments directed at bony metastases and other pain sources.

Among these, there are those known as neuro-ablation techniques and those known as neuro-modulation techniques, which may be further subdivided in electrical and pharmacological.

In patients with pain that is controlled by opioids but who experience intolerable side effects during systemic administration, an epidural or intrathecal administration may be more tolerable, as smaller doses of opioid are required to get the same analgesic effect $[11,18,20,22,23]$. These methods are 
typically performed in high proficiency pain centres and hospitals.

Nevertheless, interventional techniques remain an important and frequently underused part of the multimodal management of cancer pain. The indications for administration of strong opioids by intrathecal or epidural routes remain controversial. It has been suggested that $8-11 \%$ of carefully selected cancer patients could benefit from interventional procedures $[10,18,22]$.

\section{CONTINUITY OF CARE}

Continuity is the extent to which a chain of distinct care interventions is experienced as coherent, connected, and consistent with the patient's medical needs and personal context; it encompasses two main elements: long-term and patient-centred care [24]. There are three types of care continuity:

- Informational, where individual information on past events and personal status are used to make care appropriate.

- Management, where an appropriate approach is tailored to the patient's changing needs.

- Relational, where a persistent curative association is held between a patient and his/her providers.

Type and setting of care influence the operating type of continuity [24].

For the cancer patient, continuity of care means continuity between treatments (cancer and palliative care) or between different care providers. Care shift may occur at any point along the disease course. It is coordinated fluent transition between primary care providers and oncologists or between care in a cancer centres and home care, community or hospital. Thus, the use of care coordination mechanisms and expert support is required. The literature indicates that family physicians and community-based care providers are willing to provide palliative care if they are adequately supported by expert advice and enabled to increase their skills and confidence in providing such care. Such integration may result successful if palliative care is integrated immediately after the disease is diagnosed and if the palliative care services occupy a significant place in the cancer centre [8].

Palliative care is necessarily multidisciplinary. It is unlikely to expect single clinician to have the expertise to formulate the necessary assessment, perform the neces- sary interventions, and to deliver constant monitoring [25]. From the practical point of view "collaborative care" might be a better way to describe the fluent transition of care. Combination of palliative care and cancer treatment is the synchronised involvement of palliative and curative care throughout the disease course. Synchronisation and communication between palliative care and cancer treatment clinicians and programs are imperative. Such approach is often seen within a cancer treatment centre; however, as care is often also provided in hospital settings both for acute crisis and on outpatient consultation basis [8], synchronisation and communication are needed there as well.

\section{CONTINUITY OF CARE AND INTEGRATION OF CARE}

In cancer palliative care, continuity of care is the transition of the responsibility for care from the curative cancer treatment providers to a palliative care provider (a primary care physician, a home care team, or a hospice team) [26]. Integration of palliative care into curative cancer treatment can be defined as the provision of palliative care both during curative cancer treatment and after curative treatment has ceased. Integration is often an indicator that continuity of care will also occur. It has been reported that care is improved by introducing palliative care upstream through integration in existing clinical care settings [27].

Palliative care may be introduced downstream or upstream. In terms of continuity of care, best practices refers to those that introduce palliative care upstream during cancer treatment (as opposed to downstream, where palliative care is provided mainly at the end-of-life stage of the disease) and that involve the primary care physician. Introducing palliative care downstream undermines the fluent continuity of care. The best provision of continuity of care is by primary care physicians and community-based care when adequate home and community care is provided and is linked to hospitals and treatment centres. In some cases, cancer centres provide their own home or continuing care service.

It is crucial to underline that while facilities and availability of home and community care may favour the continuity of care, adequate, honest and open communication with patients and families are evenly essen- 
tial [28]. During each step of the disease, clinicians have to provide individualised patient-centred communications to outline treatment options in a shared decision-making process which may guarantee a tailored continuity of care. In this way, the transition from curative cancer treatment to palliative care can occur in a shared, awarded and nontraumatic way [29].

The literature on integration of palliative care and curative cancer treatment generally describes programs developed within tertiary care hospitals and cancer treatment centres or in close association with them.

Integration of palliative and curative care is a growing trend that facilitates access to palliative care upstream, rather than downstream, allows better pain and symptoms control, psychosocial support, public health benefits, and quality of life $[1,2,4]$. Integrated programs in cancer centres typically include clinical and psychosocial inpatient services (often a palliative care unit), day or outpatient clinics, link to community-based end-of-life care services such as hospice, education and research $[2,27,30]$. Among others, one example may be the National Cancer Institute in Milan, Italy (www.istitutotumori.mi.it). This institute provides research, palliative care, pain therapy, and rehabilitation programs for both in- and outpatients [8,31]. Another example is the ANT Italia Onlus Foundation in Bologna, Italy (http://www.ant.it). The latter is a nonprofit Foundation which guarantees social and clinical assistance to cancer patients and their families in 9 regions of Italy. Clinical assistance, delivered by specialised physicians, psychologists, and nurses, includes all aspects of advanced-cancer patient homecare from diagnosis to the treatment of symptoms. This foundation has strong research and clinical collaboration link with the Bologna University-Teaching-Hospital pain centre, Italy [32].

\section{THE HOSPITAL SETTING}

A further aspect of integration of palliative care into other medical milieu concerns the role of palliative care in acute or emergency contexts both for out- and inpatients. Many cancer patients will be admitted to hospital during the disease or late in life and die in acute care. They may be undergoing curative treatment or not, and they might have been at home but unable to remain there for a variety of reasons. The hospital may become a crucial point in the continuity and integration of palliative care both in the acute settings and as support to palliation in particularly difficult cases. Pain management is one of the pillars of palliative care integration in the hospital. In a cross-sectional survey conducted in a teaching hospital to gather benchmark data regarding pain prevalence and predictors among the entire inpatient population, moderate to severe pain was reported by $25 \%$ of the patients [33]. Interestingly high pain prevalence was found in the Cancer-Radiotherapy ward (63.3\%) while lower, yet significant, pain prevalence was found in the Oncology ward (32.3\%). In this study, protracted hospitalisation and prolonged pain duration were associated with major pain severity, while predictor analysis suggested that attention should be paid to pain management in young adults, socially vulnerable patients and those with protracted hospitalisation and pain, like cancer patients. Hospital pain clinics are now made available all over Italy. They deliver pain management both for inpatients and outpatients. Among the main elements that a tertiaryteaching-hospital pain clinic may offer to the palliative care network are:

- Pain management follow-up for outpatients and inpatients.

- Pain management consultation and expert support to primary care physicians and to community or home-care cancer facilities.

- Interventional procedures and techniques in pain management.

- Innovative pain management trials.

- Pain management research and education.

\section{COMMUNICATION AND PSYCHOLOGICAL FACTORS}

Continuity of care is achieved by bridging single care interventions in the care pathway as well as by supporting aspects such as patients' values and patient beliefs, sustained relationships, and care plans. For most patients, physical pain is only one of the symptoms experienced during the disease. Relief of pain should therefore be seen as part of a comprehensive pattern of care which may include the physical, psychological, social, and spiritual aspects of suffering. These components should be addressed simultaneously. In many cases of resistant pain, psychological factors play a central role in the experience of pain. Although emotional aspects don't cause pain 
directly, they contribute to a person's perception of pain and its effects, and they can influence the response to pain and treatment [34]. In order to improve the quality of life of these patients, literature suggests to associate cognitive-behavioural interventions to pharmacological pain treatment. These psychoeducational interventions are usually utilised to treat symptom clusters, like pain, fatigue and sleep disturbance [35].

For continuity to exist, care must be experienced as persistent and linked. The experience of continuity may differ for patients and providers. Among patients and their families, the perception of continuity is achieved when providers are aware of past medical events, different providers concur with the care plan, and the acquainted caregiver will provide care also in the future. For providers, the perception of continuity is achieved when they have adequate information regarding the patient to best apply their expertise and the assurance that their professional decisions will be accepted by other providers. While continuity may vary in different care contexts, continuity can contribute to ameliorate quality of care.

An efficient communication to patients and families should consider their very own concept of continuity of care by understanding the patient's current beliefs, his/her needs for information and role preferences in decision-making involvement. Individualised approach instead of a "one-size-fitsall approach" to communication grants the quality of clinicians-patient communication [36].

\section{CONCLUSIONS AND FINAL CONSIDERATIONS}

The essential components of palliative care are effective control of symptoms and effective communication with patients, their families, and whoever is involved in their care process.

While opioids are the main stem of cancer pain therapy, some pains are resistant to opioid treatments. Adjuvant drugs, radiotherapy, and anaesthetic block techniques may be considered in such cases.

As the disease progresses, continuity of care becomes more and more important: coordination between care providers is imperative, and information must flow punctually and efficiently between professionals in all care contexts and also towards patients and their caregivers.

More research is needed to find out which interventions aiming to improve continuity of care in the follow-up of cancer patients are the most beneficial to improve patient, provider and process of care outcomes and to identify which outcomes are the most sensitive to change and the most meaningful regarding continuity of care. Of crucial importance would be the development of a standardised instrument to measure the continuity of care in cancer patients.

\section{Keypoints}

- In Italy, free access to pain management in cancer and non-cancer patients is now considered a human right

- Palliative care is based on the stepwise approach reported in the WHO pain ladder; after the last step, a further step could be included in the ladder for those whose pain is resistant even to strong opioids: interventional procedures and techniques

- Pain management should be introduced upstream during cancer treatment, at the time of diagnosis, instead of being provided just at the end-of-life stage

- Continuity of care among health care professionals, wards and hospitals and communication with patients and their caregivers are pillars of a correct management of cancer pain

\section{REFERENCES}

1. Callaway M, Ferris FD. Advancing palliative care: the public health perspective.J Pain Symptom Manage 2007; 33: 483-5; http://dx.doi.org/10.1016/j.jpainsymman.2007.02.030

2. Stjernsward J, Foley KM, Ferris FD. The public health strategy for palliative care.J Pain Symptom Manage 2007; 33: 486-93; http://dx.doi.org/10.1016/j.jpainsymman.2007.02.016 
3. Brennan F. Palliative care as an international human right. J Pain Symptom Manage 2007; 33: 494-9; http://dx.doi.org/10.1016/j.jpainsymman.2007.02.022

4. Sepulveda C, Marlin A, Yoshida T, et al. Palliative Care: the World Health Organization's global perspective. J Pain Symptom Manage 2002; 24: 91-6; http://dx.doi.org/10.1016/S08853924(02)00440-2

5. Rothwell PM. Treating individuals 2. Subgroup analysis in randomised controlled trials: importance, indications, and interpretation. Lancet 2005; 365: 176-86; http://dx.doi.org/10.1016/ S0140-6736(05)17709-5

6. Trusheim MR, Berndt ER, Douglas FL. Stratified medicine: strategic and economic implications of combining drugs and clinical biomarkers. Nat Rev Drug Discov 2007; 6: 287-93; http://dx.doi. org/10.1038/nrd2251

7. Stjernsward J, Foley KM, Ferris FD. Integrating palliative care into national policies. J Pain Symptom Manage 2007; 33: 514-20; http://dx.doi.org/10.1016/j.jpainsymman.2007.02.031

8. Cancer Journey Action Group. Cancer and palliative care: integration and continuity of care. 2009. Disponibile all'indirizzo http://www.partnershipagainstcancer.ca/wp-content/uploads/3.2.2.8PEOLC_Continuity_of_Care.pdf (ultimo accesso settembre 2014)

9. Institute of Medicine. Improving palliative care for cancer. Washington DC: National Academies Press, 2001

10. NICE National Institute for Health and Care Excellence. Improving supportive and palliative care for adults with cancer. 2004. Disponibile all'indirizzo http://www.nice.org.uk/guidance/ csgsp/resources/improving-supportive-and-palliative-care-for-adults-with-cancer-manualsecond-consultation2 (ultimo accesso settembre 2014)

11. Meier DE, Brawley OW. Palliative care and the quality of life. J Clin Oncol 2011; 29: 2750-2; http://dx.doi.org/10.1200/JCO.2011.35.9729

12. World Health Organization. National cancer control programmes: policies and managerial guidelines. $2^{\text {nd }}$ edition. Ginevra, Svizzera: World Health Organization, 2002. Disponibile all'indirizzo http://www.who.int/cancer/media/en/408.pdf (ultimo accesso settembre 2014)

13. Servizio sanitario regionale Emilia Romagna. Gruppo Tecnico della Rete delle Cure Palliative Agenda del sollievo, 2012. Disponibile all'indirizzo http://www.ausl.bologna.it/liberi-dal-dolore/ liberi-dal-dolore/?searchterm=agenda\%20del\%20sollievo (ultimo accesso settembre 2014)

14. World Health Organization. Traitement de la douleur cancéreuse. Ginevra, Svizzera: World Health Organization; 1987

15. World Health Organization. Traitement de la douleur cancéreuse. Deuxième édition. Ginevra, Svizzera: World Health Organization; 1997. Disponibile all'indirizzo http://whqlibdoc.who. int/publications/9242544825.pdf (ultimo accesso settembre 2014)

16. Azevedo São Leão Ferreira K, Kimura M, Jacobsen Teixeira M, et al. The WHO analgesic ladder for cancer pain control, twenty years of use. How much pain relief does one get from using it? Support Care Cancer 2006; 14: 1086-93; http://dx.doi.org/10.1007/s00520-006-0086-x

17. Jadad AR, Browman GP. The WHO analgesic ladder for cancer pain management. Stepping up the quality of its evaluation. JAMA 1995; 274: 1870-3; http://dx.doi.org/10.1001/ jama.1995.03530230056031; http://dx.doi.org/10.1001/jama.274.23.1870

18. de Courcy JG. Interventional techniques for cancer pain management. Clin Oncol (R Coll Radiol) 2011; 23: 407-17; http://dx.doi.org/10.1016/j.clon.2011.04.003

19. Meuser T, Pietruck C, Radbruch L, et al. Symptoms during cancer pain treatment following WHO-guidelines: a longitudinal follow-up study of symptom prevalence, severity and etiology. Pain 2001; 93: 247-57; http://dx.doi.org/10.1016/S0304-3959(01)00324-4

20. Miguel R. Interventional treatment of cancer pain: the fourth step in the World Health Organization analgesic ladder? Cancer Control 2000; 7: 149-56

21. Zech DF, Grond S, Lynch J, et al. Validation of World Health Organization Guidelines for cancer pain relief: a 10-year prospective study. Pain 1995; 63: 65-76; http://dx.doi.org/10.1016/03043959(95)00017-M

22. Aubin M, Giguere A, Martin M, et al. Interventions to improve continuity of care in the followup of patients with cancer. Cochrane Database Syst Rev 2012; 7: CD007672

23. Miguel R. Understanding and managing cancer pain. Cancer Control 2000; 7: 97-8

24. Haggerty JL, Reid RJ, Freeman GK, et al. Continuity of care: a multidisciplinary review. BMJ 2003; 327: 1219-21; http://dx.doi.org/10.1136/bmj.327.7425.1219

25. O'Neill B, Fallon M. ABC of palliative care. Principles of palliative care and pain control. BMJ 1997; 315: 801-4; http://dx.doi.org/10.1136/bmj.315.7111.801 
26. Dumont I, Dumont S, Turgeon J. Continuity of care for advanced cancer patients. J Palliat Care 2005; 21: 49-56

27. Byock I, Twohig JS, Merriman M, et al. Promoting excellence in end-of-life care: a report on innovative models of palliative care.J Palliat Med 2006; 9: 137-51; http://dx.doi.org/10.1089/ jpm.2006.9.137

28. Smith TJ, Temin S, Alesi ER, et al. American Society of Clinical Oncology provisional clinical opinion: the integration of palliative care into standard oncology care. J Clin Oncol 2012; 30: 880-7; http://dx.doi.org/10.1200/JCO.2011.38.5161

29. Dizon DS, Politi MC, Back AL. The power of words: discussing decision making and prognosis: 213 ASCO Educational Book. 2013. Disponibile all'indirizzo http://meetinglibrary.asco.org/ content/242-132 (ultimo accesso settembre 2014)

30. Ferris FD, Balfour HM, Owen K, et al. A model to guide hospice palliative care. Based on national principles and norms of practice. 2002. Disponibile all'indirizzo http://www.chpca. net/media/7422/a-model-to-guide-hospice-palliative-care-2002-urlupdate-august2005.pdf (ultimo accesso settembre 2014)

31. Porzio G, Ricevuto E, Aielli F, et al. The Supportive Care Task Force at the University of L'Aquila: 2-years experience. Support Care Cancer 2005; 13: 351-5; http://dx.doi.org/10.1007/ s00520-004-0772-5

32. Melilli G, Samolsky Dekel BG, Frenquelli C, et al. Transdermal opioids for cancer pain control in patients with renal impairment. J Opioid Manag 2014; 10: 85-93; http://dx.doi.org/10.5055/ jom.2014.0197

33. Melotti RM, Samolsky-Dekel BG, Ricchi E, et al. Pain prevalence and predictors among inpatients in a major Italian teaching hospital. A baseline survey towards a pain free hospital. Eur J Pain 2005; 9: 485-95; http://dx.doi.org/10.1016/j.ejpain.2004.09.010

34. Raphael J, Ahmedzai S, Hester J, et al. Cancer pain: part 1: Pathophysiology; oncological, pharmacological, and psychological treatments: a perspective from the British Pain Society endorsed by the UK Association of Palliative Medicine and the Royal College of General Practitioners. Pain Med 2010; 11:742-64; http://dx.doi.org/10.1111/j.1526-4637.2010.00840.x

35. Kwekkeboom KL, Abbott-Anderson K, Cherwin C, et al. Pilot randomized controlled trial of a patient-controlled cognitive-behavioral intervention for the pain, fatigue, and sleep disturbance symptom cluster in cancer.J Pain Symptom Manage 2012; 44: 810-22; http://dx.doi.org/10.1016/j. jpainsymman.2011.12.281

36. Brundage MD, Feldman-Stewart D, Tishelman C. How do interventions designed to improve provider-patient communication work? Illustrative applications of a framework for communication. Acta Oncol 2010; 49: 136-43; http://dx.doi.org/10.3109/02841860903483684 